\title{
Por que é relevante a ambientação e a aculturação visando pesquisas qualitativas em serviços para dependência química?
}

\author{
Why is environmental adaptation and acculturation relevant \\ when seeking to conduct qualitative research \\ in drug dependency services?
}

Dione Viégas de Almeida Ribeiro ${ }^{1}$

Renata Cruz Soares de Azevedo ${ }^{1}$

Egberto Ribeiro Turato ${ }^{1}$

${ }^{1}$ Departamento de Psicologia Médica e Psiquiatria, Faculdade de Ciências Médicas, Universidade Estadual de Campinas. Cidade Universitária Zeferino Vaz. Caixa Postal 6111. 13083-970 Campinas SP erturato@uol.com.br

\begin{abstract}
This study conducted at the Outpatient Service of Psychoactive Substances, in the University General Hospital of Campinas, sought to report on an experience of proactive participation to study the life experience of chemically dependent patients attended in a specialized university service. These observations emerged from the researcher's experiences in the environmental adaptation and acculturation period, namely through the researcher insertion in the outpatient service, during the preliminary data collection for qualitative research. This experience was important as it enabled clearer comprehension of the psycho-cultural universe of the population attended and how the relation professional-patient is conducted, broadening the knowledge of the field where the research was later carried out. From this initial entry in the field, it was possible to define the subject-matter and the population being studied more clearly, adapting to the needs and the reality observed in that service, as well as to reflect on the research method that serve to better understand the issues raised, and even draw up a roadmap for future interviews in the study. It was concluded that this preliminary stage is very useful as standard practice in new studies using the same methodology in clinical settings.
\end{abstract}

Key words Acculturation, Substance-related disorders, Qualitative research
Resumo Este trabalho realizado no Ambulatório de Substâncias Psicoativas do Hospital das Clínicas da Unicamp, objetivou relatar uma experiência de entrada em campo como fator de facilitação do estudo das vivências de sujeitos dependentes químicos vistos em um serviço universitário especializado. As observações surgiram a partir das vivências da pesquisadora em fase de ambientação e aculturação, ou seja, a partir da inserção no ambulatório, em fase preliminar à coleta de dados para uma pesquisa qualitativa. A experiência foi importante, pois permitiu compreender melhor o universo psicocultural da população atendida e como se dão as relações profissional-paciente, ampliando o conhecimento do campo onde depois foi realizada a pesquisa. A partir desta entrada inicial em campo, delimitou-se melhor o tema e a população a ser pesquisada, adequando às necessidades e à realidade observada naquele serviço, bem como refletir sobre o método de pesquisa (clínico-qualitativo) que melhor serviria para compreender as questões levantadas, e, inclusive, elaborar um roteiro para as futuras entrevistas do estudo. Conclui-se ser muito útil esse momento preliminar como fase habitual em novas pesquisas que usem a mesma metodologia nos settings clínicos.

Palavras-chave Aculturação, Transtornos relacionados ao uso de substâncias, Pesquisa qualitativa 


\section{Introdução}

O presente artigo pretende discutir a relevância da aproximação do objeto de uma pesquisa e do lugar onde esta se desenvolverá, através de estratégias de ambientação e de aculturação. Optamos por vivenciar um primeiro momento de ambientação e aculturação em um ambulatório universitário para dependentes de substâncias psicoativas (SPA), visando posterior pesquisa utilizando o método clínico-qualitativo.

A antropologia e a psicanálise, dentre outras áreas do conhecimento científico, têm feito uso, historicamente, dos chamados métodos qualitativos, desde o início do Século 20. Posteriormente, as disciplinas científicas da área da educação, das ciências sociais, das ciências da saúde e da psicologia também passaram a se valer desses métodos. Essas disciplinas são consideradas pertencentes ou associadas às Ciências Humanas, as quais visam compreender e interpretar os nexos de significados presentes nos fenômenos individuais e sociais ${ }^{1}$.

Um amplo estudo de revisão bibliográfica apontou que, ao longo dos anos, constituiu-se um representativo campo para estudos sobre a construção científica na área das ciências sociais em saúde. Na década de 60 surgiram no Brasil importantes cientistas sociais, muitos como autodidatas em questões da Saúde, começando trabalhos multiprofissionais especialmente voltados para a comunidade. O material que surge desses trabalhos - e que incorpora tanto um conhecimento dos aspectos médicos, assim como sociais, culturais e psicológicos - pretendia ser uma aproximação interdisciplinar e conduzia a um retrato biopsicossocial ${ }^{2-3}$.

Ao buscar um refinamento da compreensão de significados pessoais atribuídos aos diversos fenômenos observados, especificamente em settings da Saúde, e considerando a experiência clínica do pesquisador, o método eleito para este estudo conduzido em serviço ambulatorial universitário de referência, é o clínico-qualitativo. Este nasce da necessidade de uma estruturação metodológica específica com os cuidados clínicos com a saúde, nomeadamente ao sofrimento existencial e psicológico, associados às manifestações no processo saúde-doença ${ }^{4}$.

Quando se pretende utilizar uma metodologia qualitativa, na compreensão de um fenômeno ou setting, faz-se fundamental antes de qualquer intervenção, conhecer bem o campo em que se dará a coleta dos dados, ainda que não lacemos mão do trabalho etnográfico propriamente dito.
"Na virada do século XIX para o XX, localizase o projeto de uma Antropologia do indivíduo e da singularidade cultural, projeto que se opõe à anterior tendência de buscar a universalidade do homem nos estudos comparativos das diferentes culturas. É, ainda nesta virada de séculos que a Antropologia moderna, se institui como ciência"5.

Nesse momento surge então, o interesse em conhecer o indivíduo imerso em sua cultura. Essa Antropologia moderna exige então uma postura do pesquisador de observação participante, dando origem aos métodos atuais de pesquisa etnográfica, na qual o observador é também inserido na cultura que pretende pesquisar ${ }^{5}$.

A pesquisa etnográfica privilegia a observação sistemática das situações reais no local onde os fenômenos ocorrem. Esse tipo de pesquisa não se configura como uma aplicação de uma técnica, mas vai se desenvolvendo "na medida em que o pesquisador vai se imbricando no campo, vai se relacionando com os sujeitos e construindo um processo reflexivo sobre suas vivências e impressões" ${ }^{\text {. }}$

O antropólogo Bronislaw Malinowiski se tornou referência primordial para estudos clássicos, desenvolvidos pioneiramente em trabalho de campo com nativos em cultura do extremo oriente. Para ele, o trabalho de campo deveria produzir uma visão autêntica da vida da comunidade em estudo, devendo-se ultrapassar alguns obstáculos, tais como a falta de domínio da língua nativa, os preconceitos e opiniões de pessoas externas ao grupo observado. O trabalho de campo também deveria estar integrado a problematizações teóricas ao propiciar um contato, o mais íntimo possível, na perspectiva do grupo estudado ${ }^{7}$.

Trabalhos em campo constituem-se etapa central da pesquisa qualitativa em saúde. Nesse tipo de pesquisa, é crucial uma relação de intersubjetividades e de interação social com o pesquisador, que resulte em conhecimentos novos, que podem ser confrontados com a realidade concreta e com pressupostos teóricos, gerando uma construção mais ampla de saberes ${ }^{8}$.

Este artigo trata de descrever as experiências de entrada em campo, as quais são chamadas de aculturação e ambientação, mas que não se trata de uma etnografia, mas parte da importância destacada em trabalhos etnográficos ao conhecimento prévio da população e ambiente a serem estudados.

É descrito em literatura como etapa anterior ao trabalho da pesquisa de campo propriamente dita, a fase exploratória, na qual serão definidos: o espaço da pesquisa, o grupo a ser pesquisado, os critérios de amostragem e a estratégia de en- 
trada em campo ${ }^{8}$. Sempre considerando que a pesquisa qualitativa preocupa-se com o aprofundamento e a abrangência da compreensão seja de um grupo humano, de uma organização ou de uma instituição. É necessário à pesquisa qualitativa conhecer amplamente os sujeitos envolvidos, com idas repetidas a campo, antes do trabalho de coleta propriamente dito. Tal fase de ambientação e aculturação permite o fluir da rede de relações e possíveis correções iniciais dos instrumentos da futura coleta formal de informações ${ }^{8}$.

Pressupõe-se que, a todo pesquisador que parte para a fase da investigação em settings, é necessário essa fase de ambientação e aculturação, em espaço de tempo se não longo, porém em profundidade. O termo ambientação está aqui entendido como a adaptação geral à rotina do setting onde se coletarão os dados, bem como a aquisição de informações sobre o cotidiano das pessoas que ali trabalham e daquelas que são atendidas no local. Por sua vez, aculturação, conceito mais abrangente, pressupõe um contato com a incorporação das mentalidades, costumes e valores da população deste campo de investigação9

Apesar de propormos os processos de ambientação e aculturação de forma simultânea e complementar, devemos apontar que, conforme definições anteriores, são conceitos diferentes e, por vezes, podem ter pesos diferentes em uma pesquisa de campo, sendo priorizado ora um, ora outro.

Turato ${ }^{4}$ acrescenta, ainda: havendo uma adaptação do pesquisador, a partir da ambientação e da aculturação, ao espaço do serviço de saúde onde ocorrerá a pesquisa, à rotina de trabalho, aos hábitos, à linguagem e à problemática vivenciada, poderá ser construído um setting, um ambiente delimitado para a realização das futuras entrevistas.

A necessidade desse momento de ambientação e aculturação surge com a necessidade de transpor barreiras que afastam pesquisador e pesquisado. Conhecer anteriormente a rotina de trabalho, a linguagem utilizada, a problemática ali exposta, é fundamental para que se possa realizar uma pesquisa qualitativa de forma mais apurada e com menos vieses ${ }^{4}$.

Na pesquisa qualitativa em Ciências Sociais, o estudo etnográfico é a principal ferramenta utilizada para se conhecer mais profundamente uma população. Este se dá exatamente a partir da inserção do pesquisador no ambiente a ser estudado, por um espaço de tempo por vezes prolongado, com contato direto com o objeto de estudo, sendo posteriormente relatado em texto, de forma sistemática ${ }^{10}$.
Verificamos na literatura a importância de se buscar uma maior aproximação do grupo a ser estudado, não apenas para se conhecer melhor as especificidades do mesmo, mas também para que o pesquisador seja previamente aceito pelos sujeitos, posto que a qualidade dos dados obtidos depende, em grande parte, de como se dá a relação entre sujeito e pesquisador. "Dessa forma é possível manter uma relação dialógica, de proximidade e confiança, baseada em princípios éticos" ${ }^{10}$.

Leite e Vasconcellos ${ }^{11}$, também apontam que a entrada em campo e o contato inicial com os informantes merecem atenção especial por determinarem o início de uma relação que pretende ser de confiança. Sendo que, quando o pesquisador consegue assimilar a linguagem e o universo cultural do grupo em estudo, ocorre uma maior aceitação por parte dos seus interlocutores e a interação entre eles pode ser aprofundada. Todavia, tal interação é um processo que demanda tempo, por isso a necessidade de uma aproximação do grupo, antes do início da pesquisa propriamente dita.

Clifford ${ }^{12}$ aponta a importância de se construir "um mundo de experiências partilhadas, em relação ao qual todos os 'fatos', 'textos', 'eventos' e suas interpretações serão construídos”. A qual se dá a partir da experiência do pesquisador em campo, com seus sentimentos intuitivos, percepções e inferências.

A observação participante exige um bom aprendizado da língua ou mesmo da linguagem do grupo estudado em sentido amplo, o que favorece ainda certo grau de envolvimento. Também é preciso algum despojamento das expectativas pessoais e culturais do observador ${ }^{12}$.

Paul Rabinow ${ }^{13}$, também demonstra em seus trabalhos etnográficos um cuidado com as pessoas envolvidas. Buscando estar "separado o suficiente para evitar uma identificação fácil, próximo o suficiente para compreender de uma forma benevolente, embora crítica".

O antropólogo Roberto da Mata ${ }^{14}$ afirma que para escrever uma boa etnografia é necessário aproximar-se empaticamente das pessoas do grupo estudado, mas também perceber-se solitário em seu trabalho de observação. Podendo entrar em contato com os sentimentos despertados ao relacionar-se com essas pessoas. Ele propõe também a tarefa de transformar o "exótico em familiar e o familiar em exótico". O primeiro caso corresponde ao movimento original da Antropologia, mas a segunda transformação proposta visa estranhar algo em nosso quotidiano familiar, "o exótico no que está petrificado dentro 
de nós pela reificação e pelos mecanismos de legitimação".

A partir do que conhecemos em estudos anteriores, apontados nesta revisão bibliográfica, compreendemos ser fundamental haver um contato prévio com o grupo a ser estudado, sem ambicionarmos o trabalho de um etnógrafo, treinado para esses fins, mas ainda buscando nos familiarizar com o grupo a ser pesquisado, sua linguagem e seu modo de funcionamento. Acreditando que o conhecimento acerca de um grupo se dá de forma constante, como uma construção, que inclusive só se faz possível com a figura do pesquisador inserida naquele grupo e atento aos seus próprios movimentos internos, por isso propõe-se a aculturação e a ambientação.

Entre as subáreas que compõe a saúde mental, algumas se beneficiam particularmente da aproximação do objeto em função de especificidades relacionadas aos sujeitos, ao contexto e à visão social do tema, entre outras. Neste sentido o estudo de temas relacionados ao consumo de substâncias psicoativas merece particular atenção.

O uso de substâncias psicoativas, com maior repercussão social, é um fenômeno relativamente recente. Embora o consumo de drogas psicoativas seja milenar, seu uso só se tornou um problema social amplo, na maior parte dos países ocidentais, a partir do quarto final do século XIX, com a criminalização e a medicalização dessas substâncias. Tal ocorreu inicialmente nos EUA, em função de movimentos religiosos e sociais, e, principalmente, por interesses de ordem econômica ${ }^{15}$.

A dependência de Substâncias Psicoativas (SPA) é considerada pela Organização Mundial de Saúde (OMS) como um transtorno mental e do comportamento. A Classificação Internacional das doenças (CID-10) e o Manual Diagnóstico e Estatístico de Transtornos Mentais norteamericano (DSM-IV) discriminam os principais quadros relacionados ao uso de SPA, bem como a dependência, caracterizada de forma semelhante em ambos, a saber: um desejo pronunciado de tomar a substância; dificuldade em controlar o uso; estado de abstinência fisiológica; tolerância; relegar a um segundo plano as necessidades, interesses e atividades prazerosas; e uso persistente, não obstante os danos causados à própria pessoa e aos outros; e por fim, um critério que descreve um padrão intermediário entre uso e dependência que é o uso nocivo ou abuso ${ }^{16-17}$.

Para a compreensão dos diversos aspectos da dependência de SPA faz-se necessária a existência de um enfoque abrangente, que leve em consideração a diversidade de usos e de comportamentos, tanto em relação aos produtos como em relação ao contexto social em que ocorrem. A especificidade das dependências químicas procede do encontro do indivíduo com uma SPA em um determinado contexto sociocultural. $\mathrm{O}$ uso indevido de drogas, como dito, constitui fenômeno de grande complexidade, não podendo ser reduzido a componentes biológicos, nem compreendido apenas a partir de aspectos da conduta dependente ou da psicodinâmica envolvida, mas pensando que todos estes enfoques estão presentes concomitantemente e se influenciam mutuamente ${ }^{18}$. Sendo que, em função de tais especificidades, a dependência química se faz presente não apenas no campo da saúde, mas também em campos como o jurídico e o sociológico.

A dependência química, também é uma área envolta em preconceitos, e mesmo entre os especialistas há divergências nas formas de compreender a problemática e atuar junto a essa população. Assim sendo, uma aproximação anterior do objeto de estudo, pode ser fundamental para minimizar a possibilidade de haver uma imposição de um olhar contaminado com ideias preconceituosas, ao trabalho de pesquisa propriamente dito.

Portanto, o olhar antropológico sobre a forma de se fazer pesquisa em saúde, pode ser muito útil nos estudos em dependência de SPA. Ele favorece aqueles voltados para as relações entre saúde e condições de vida, incorporando também a visão do sujeito, por exemplo, o usuário de um serviço de saúde. Deve buscar um redimensionamento dos limites da ciência, ampliando a sua interação com outras formas de apreender a realidade. Com isso, abre-se espaço para novas formas de construção científica que expliquem a realidade ${ }^{19}$.

Neste relato, mencionamos a experiência da ambientação e da aculturação da pesquisadora em ambulatório universitário especializado, voltado para tratamento de dependência de SPA. Fundamental foi conhecer intimamente a realidade de um serviço de saúde, a linguagem das pessoas ali atendidas e as dinâmicas das relações envolvidas a fim de se ter inserção suficiente para o subsequente trabalho de pesquisa na abordagem qualitativa.

Buscamos com este trabalho relatar uma experiência de entrada em campo como fator de facilitação do estudo das vivências de sujeitos dependentes químicos vistos em um serviço universitário de especialidade psiquiátrica. 
Relato de vivências da pesquisadora frente à estruturação do campo (percurso dos procedimentos)

Contextualizando a descrição do campo, o trabalho aqui apresentado deu-se a partir da inserção da pesquisadora, mestranda do Programa de PósGraduação em Ciências Médicas da Faculdade de Ciências Médicas da Unicamp, no serviço assistencial de seu hospital público de referência. O Ambulatório de Substâncias Psicoativas (ASPA) é parte do conjunto de ambulatórios psiquiátricos do Hospital das Clínicas de Campinas (HC/UNICAMP) e atende principalmente à população do Município e Região. Os atendimentos são semanais para os habitantes locais, enquanto pessoas vindas de municípios distantes ou mesmo de outros estados são atendidas para devida avaliação e encaminhamento a serviços próximos à localidade de origem. O atendimento é integralmente gratuito e a entrada no serviço é ágil, todos que procuram o serviço são imediatamente inseridos no ambulatório, já iniciando participação em grupos. A inserção no ambulatório independe de encaminhamentos via rede básica de saúde.

A população ambulatorial é composta principalmente por adultos que têm o diagnóstico de dependência de álcool, tabaco e/ou drogas ilícitas, sendo frequente a existência de comorbidades clínicas e/ou psiquiátricas. Os pacientes participam inicialmente de um grupo de recepção onde se trabalha a motivação para o tratamento, sendo propostas reflexões sobre as consequências da droga em sua vida, o real desejo de mudança, de deixar ou de diminuir o uso de substâncias. Os pacientes também são atendidos individualmente por médicos residentes de psiquiatria, para devida avaliação clínica e possível farmacoterapia. Após estas etapas, alguns grupos são oferecidos, conforme o indicado a cada pessoa. Para álcool e outras drogas, há o grupo que trabalha técnicas de prevenção à recaída e o grupo no qual são fornecidas informações sobre as drogas, sua constituição e efeitos a curto e longo prazo, bem como o grupo de apoio para familiares. Para tabagistas, há um grupo onde se trabalha a motivação para o tratamento e o abandono do hábito de fumar, e um grupo terapêutico. Além dos médicos residentes, atuam nos atendimentos: psicólogos, assistentes sociais, enfermeiros e auxiliares de enfermagem; todos, de algum modo, vinculados à Unicamp, como funcionários, estagiários ou voluntários. Lembrando que se trata de um hospital-escola e, assim sendo, os atendimentos geralmente são acompanhados por alunos-observadores.
Este período de ambientação e aculturação foi uma fase preliminar à coleta de dados de uma pesquisa qualitativa, marcada pela observação do campo. A pesquisadora esteve presente no ambulatório uma vez por semana, no período da manhã, durante seis meses consecutivos, até o início da pesquisa propriamente dita. Acompanhou as discussões de casos clínicos conduzidas por equipe multiprofissional, e também frequentou seminários teóricos. Participando do ASPA, a pesquisadora teve ainda a oportunidade de dirigir um grupo informativo, a cada dois meses, sendo responsável por discutir aspectos psicológicos da dependência de SPA em reuniões. Também conduziu um grupo motivacional misto, de frequência semanal. Nele, pacientes são atendidos antes mesmo de passarem por consulta médica, sendo um momento de recepção, uma primeira escuta sobre o que os levou a buscar esta ajuda. É desempenhada uma tarefa que, além de oferecer uma escuta para as angústias trazidas, visa fortalecer a motivação para o tratamento.

\section{Reflexões acerca da experiência de} ambientação e aculturação do pesquisador

O primeiro ponto que merece reflexão tratase do emprego dos conceitos de ambientação e aculturação. Em pesquisa qualitativa, não lançamos mão dos chamados pré-testes ou das entrevistas-piloto, cujo objetivo, equivalentemente, é assegurar-se de que os instrumentos de investigação estão 'regulados' para a aplicação e a coleta validadas visando o alcance dos objetivos do empreendimento. Nas pesquisas qualitativas, nas quais o pesquisador é o próprio instrumento, o entrevistador deve adquirir experiência prévia em coletar os dados adequadamente planejados ${ }^{4}$.

Neste período, de ambientação e aculturação, pôde-se conhecer de perto, além do funcionamento operacional do serviço de ambulatório, enquanto campo físico desenhado para a pesquisa, também o universo psicocultural da população atendida e como se dão as relações profissional-paciente; bem como aspectos relevantes para serem aprofundados na investigação clínico-qualitativa.

Durante o processo de ambientação e aculturação é importante destacar como foi a experiência da inserção da pesquisadora no serviço. No ASPA, foi bem aceita pelos profissionais responsáveis, sendo prontamente incluída nas discussões e atividades. Também não teve dificuldade em adaptar-se à rotina do ambulatório e compreender a linguagem ali utilizada. 
Os profissionais, particularmente os residentes, demonstraram essa boa receptividade em relação à pesquisadora, principalmente ao procurarem sua opinião nos casos atendidos por ela e também encaminhando pacientes para seu grupo. Percebeu-se nos profissionais um real propósito de ajudar seus pacientes, embora lidassem com a frustração das constantes recaídas.

As mais importantes reflexões e conclusões acerca do que era observado e experimentado em campo ocorriam, efetivamente, a posteriori. Durante a vivência no ambulatório, a pesquisadora envolvia-se de tal modo com o serviço e a agitada rotina dos atendimentos, discussões e encaminhamentos, que se sentia como membro da equipe, não como mero observador.

Verificou-se que para profissionais e pacientes uma nova ajuda, uma visão adicional sobre a problemática atendida era bem-vinda. Não se pode esquecer que se tratava de um ambulatório dentro de um hospital-escola, onde as pessoas tenderiam a ser mais receptivas a qualquer nova informação. Todavia, podemos compreender que os profissionais demonstravam uma angústia semelhante à de seus pacientes, talvez identificados com eles em seus sofrimentos, no desejo de cessar a dor. Mas, por outro lado, talvez sentindo a necessidade de dividir as angústias e os questionamentos despertados pelos atendimentos.

Conforme anteriormente descrito, a pesquisadora teve contato com os pacientes do ambulatório em dois grupos, sendo que o motivacional, por ser de frequência semanal e com menos participantes, foi o campo onde se fez a maior parte das observações. Dessa forma, é importante compreender o processo deste grupo, no qual a pesquisadora desempenhava um duplo papel, o de observadora e o de terapeuta.

O que seria então motivação? Miller e Rollni$\mathrm{ck}^{20}$ falam de motivação como um "estado de prontidão para mudança”, que varia de pessoa a pessoa, é mutável e influenciável. Portanto, um paciente pode estar mais ou menos pronto para a proposta do tratamento, mas, com um trabalho específico, pode-se favorecer a tal prontidão. Isto pode ser alcançado através de algumas estratégias propostas pelos autores anteriormente citados, a saber: oferecer orientação, remover barreiras, proporcionar escolhas, diminuir o aspecto desejável do comportamento, praticar a empatia, proporcionar feedback, esclarecer objetivos e ajudar ativamente $^{20}$.

No referido grupo motivacional, conduzido pela pesquisadora, buscava-se oferecer um momento de reflexão inicial sobre o porquê dos pa- cientes buscarem o tratamento e o que esperavam receber no ambulatório. Seguia-se pelo questionamento de como estava o envolvimento com a substância, quais as perdas acumuladas no decorrer do tempo de uso, quais objetivos de cada um com o tratamento, que atitudes poderiam ajudá-los a atingir seus objetivos. No papel de terapeuta, procurava ser empática com os problemas trazidos pelo grupo, oferecia alguns esclarecimentos sobre as substâncias e seus efeitos no organismo, e sobre os atendimentos oferecidos no ASPA, mas deixava claro que respeitaria as escolhas individuais. No decorrer do processo a terapeuta também passou a discutir com os médicos possíveis encaminhamentos.

Este papel desempenhado pela pesquisadora foi bastante enriquecedor, pois dessa forma pôde, ao mesmo tempo, estar mais próxima dos pacientes e vivenciar um pouco os papéis exercidos pelos profissionais envolvidos no serviço. Isso favoreceu uma maior compreensão das reais demandas e necessidades do ambulatório e da população nele atendida.

Essa integração entre papéis assistenciais e de investigação científica consiste em rica estratégia, já que usa este meio disponível e a condição de favorecimento com o fim de alcançar o objetivo específico da pesquisa. Pode-se considerar uma forma de se conhecer mais profundamente este campo, inclusive tendo um papel definido em um grupo, com as mesmas características da população a ser pesquisada.

Como vimos na literatura, é um elemento central em pesquisa de metodologia qualitativa a incorporação do campo, não partindo de um pressuposto dado, mas sim da construção de seu sentido, do mergulho em suas singularidades ${ }^{21}$.

Enquanto observadora do serviço em questão, a pesquisadora adotou uma postura mais ativa, não somente a de escuta, mas também participando e opinando a respeito dos casos atendidos. Ela pôde ter uma compreensão mais ampla, não apenas da dinâmica do serviço, mas também sobre a de cada paciente ali atendido. Tal compreensão, mais global e profunda, favoreceu o trabalho terapêutico da pesquisadora no grupo motivacional que coordenava, tendo obtido mais ferramentas para discutir as dificuldades trazidas pelo grupo, descrever a eles o serviço ali oferecido e a importância do tratamento.

Ocupando o lugar de observadora/terapeuta a pesquisadora pôde se aproximar do grupo, buscando tornar familiar o ambiente (ambulatório) ainda parcialmente desconhecido, mas também buscava descobrir não necessariamente pontos 
"exóticos" em meu familiar papel de terapeuta, mas perceber aquela realidade em toda sua complexidade. Como visto na teoria, o processo de "estranhar o familiar" ocorre quando confrontamos intelectualmente, e mesmo emocionalmente, diferentes versões e interpretações pré-existentes. Haja vista que "o que sempre vemos e encontramos pode ser familiar, mas não é necessariamente conhecido e o que não vemos e encontramos pode ser exótico, mas, até certo ponto, conhecido"22.

Através desse recurso de observação participante, constatou-se que o papel de terapeuta precisa ser flexível, ora acolhendo o sofrimento, ora ensinando conceitos (como efeitos e consequências do uso de substâncias), ora motivando, ora esclarecendo ao paciente uma realidade que ele não consegue ou não quer ver. Vivenciou-se ainda o sentimento de frustração em situação de abandono do tratamento, ou recaídas dos pacientes, bem como a necessidade do terapeuta buscar em si mesmo a referida "motivação" para transmitir ao paciente.

Com relação às observações da população atendida pelo ASPA, destaca-se a importância dada pelos pacientes ao apoio sentido por parte da equipe técnica e do grupo. Na pesquisadora ficou a impressão de que, em um espaço no qual os pacientes pudessem falar livremente de seu sofrimento frente à substância e ouvir relatos de companheiros que vivenciam situações semelhantes, seria uma ajuda fundamental.

Percebeu-se ser frequente o abandono do tratamento, sendo grande a rotatividade no grupo. Muitos retornavam algum tempo depois e relatavam os motivos do abandono. Verificou-se que tais motivos passavam por processos de recaída do uso, porém, foi constatado também o abandono em função da melhora do paciente, que interrompia o tratamento e seguia reconstruindo sua vida com a família e o trabalho. Havendo o retorno ao ambulatório em um momento posterior quando novamente sentiam que precisavam de ajuda.

Outro ponto rapidamente observado, foi que no grupo motivacional conduzido pela pesquisadora, havia uma quantidade maior de homens do que mulheres (cerca de sete homens para cada mulher), sendo mais frequente o abandono por parte das mulheres. Percebeu-se que estas interagiam menos nos grupos, falando quando estimuladas e demonstrando certo enfado com as falas dos companheiros homens.

Devido às diferenças constatadas durante o processo de aculturação e ambientação entre a população masculina e feminina atendida no ambulatório, decidiu-se o tema da futura pesquisa clínico-qualitativa. Percebeu-se a necessidade de compreender o significado do tratamento ali oferecido para as pacientes mulheres. Inicialmente pensamos em estudar apenas uma população de mulheres dependentes de cocaína e cra$\mathrm{ck}$, mas com o conhecimento prévio do serviço, percebemos que não haveria um número suficiente de sujeitos para a pesquisa. Assim sendo, propusemos um estudo sobre as significações psicológicas da adesão ao tratamento de mulheres dependentes de SPA.

\section{Considerações finais}

A experiência de ambientação e aculturação foi entendida como momento importante para um trabalho de investigação clínico-qualitativo, devendo ser indicado como fase habitual em novas pesquisas que utilizem a mesma metodologia nos settings clínicos. No tocante à ambientação, percebemos que um serviço ambulatorial, dentro de um hospital-escola, possui particularidades que o diferencia de outros serviços especializados em dependência. Pôde-se conhecer as limitações e as vantagens de um serviço como este, bem como perceber que a população que busca o ASPA também tem suas condições. Quanto à aculturação, esta se mostrou importante para facilitar a aproximação da pesquisadora das mulheres a serem pesquisadas, como por exemplo, ao conhecer e utilizar a linguagem verbal e gestual da referida população, que em parte servem para criar uma cultura própria de comunicação (que por vezes exclui o profissional) e por outro lado, uma vez entendida, permite uma maior compreensão de sentidos.

A pesquisadora registrou, já no primeiro contato com a população do ASPA, a importância de se oferecer uma recepção cuidadosa a pacientes que procuram tratamento em função do uso de drogas, a fim de ajudá-los a superar medos de exporem-se e de serem julgados como estão habituados. Demonstraram a necessidade de serem ouvidos e auxiliados na melhor compreensão de seus problemas.

A partir da vivência de aculturação e ambientação da pesquisadora, verificamos um aspecto relevante a ser bem estudado que é o perfil de atitudes diferentes entre os gêneros, notadamente conhecer as especificidades de um atendimento necessário a mulheres. Por conseguinte, a vivência da fase preliminar à coleta de dados em campo de pesquisa confirmou a relevância cien- 
tífica de se empreender o estudo das representações psicossociais e significações simbólicas sobre a adesão de mulheres ao tratamento especializado para dependência de SPA.

\section{Colaboradores}

DVA Ribeiro participou pesquisa em campo, discussão e redação do artigo. RCS Azevedo e ER Turato orientaram a pesquisa de campo e participaram das discussões e redação do artigo.

\section{Agradecimento}

Agradecemos a Capes pelo financiamento da pesquisa envolvida no estudo descrito neste artigo.

\section{Referências}

1. Fontanella BJB. Procura de tratamento por dependen tes de substâncias psicoativas: um estudo clínicoqualitativo [tese]. Campinas: Unicamp; 2000.

2. Nunes ED. A trajetória das ciências sociais em saúde na América Latina: revisão da produção cientí fica. Rev Saude Publica 2006; 40(N. Esp.):64-72.

3. Nunes ED. As ciências sociais em saúde: reflexões sobre as origens e a construção de um campo de conhecimento. Saúde Soc 1992; 1(1):59-84.

4. Turato ER. Tratado de metodologia da pesquisa clínico-qualitativa - construção teórico-epistemológica, discussão comparada e aplicação nas áreas de saúde e humanas. 2a Edição. Petrópolis: Editora Vozes; 2003.

5. Schmidt MLS. Pesquisa participante: alteridade e comunidades interpretativas. Psicol USP 2006; 17(2): 11-41.

6. Fontoura HA. A etnografia na saúde: tecendo perspectivas interdisciplinares. Rev Socerj 2007; 20(4): 309-312.

7. Giumbelli E. Para além do "Trabalho de Campo": reflexões supostamente malinowskianas. Rev Bras Ciênc Soc 2002; 17(48):91-107.

8. Minayo MCS. O desafio de conhecimento: pesquisa qualitativa em saúde. $10^{\text {a }}$ Edição. São Paulo: Hucitec; 2007.

9. Fontanella BJB, Campos CJG, Turato ER. Coleta de dados na pesquisa clínico-qualitativa: uso de entrevistas não-dirigidas de questões abertas por profissionais da saúde. Rev Latino-am Enfermagem 2006; 14(5):812-820.

10. Caprara A, Landim LP. Etnografia: uso, potencialidades e limites na pesquisa em saúde. Interface Comun Saúde Educ 2008; 12(25):363-376.

11. Leite SN, Vasconcellos MPC. Construindo o campo da pesquisa: reflexões sobre a sociabilidade estabelecida entre pesquisador e seus informantes. Saúde soc. 2007; 16(3):169-177

12. Clifford J. A experiência etnográfica: antropologia e literatura no século XX. Rio de Janeiro: Editora UFRJ; 2002.
13. Rabinow P. Antropologia da razão: ensaios de Paul Rabinow. Rio de Janeiro: Relume Dumará; 1999.

14. Da Mata R. O ofício de etnólogo, ou Ter "Anthropological Blues”. In: Nunes EO, organizador. A aventura sociológica. Rio de Janeiro (RJ): Zahar Editores; 1978.

15. Fiore M. Uso de "drogas": controvérsias médicas e debate público.Campinas: Mercado das Letras; 2007.

16. Organização Mundial de Saúde (OMS). Classificação de transtornos mentais e de comportamento da CID-10. Porto Alegre: Artes Médicas; 1993.

17. American Psychiatric Association (APA). Diagnostic and statistic manual of mental disorders (DSM$I V)$. Washington (DC): APA; 1994.

18. Silveira Filho DX, Gorgulho M, organizadores. Dependência: compreensão e assistência às toxicomanias: uma experiência do PROAD. São Paulo: Casa do Psicólogo; 1996.

19. Backes MTS, Rosa LM, Fernandes GCM, Becker SG, Meirelles BHS, Santos SMA. Conceitos de Saúde e Doença ao Longo da História sob o Olhar Epidemiológico e Antropológico. Rev. enferm. 2009; 17(1):111-117.

20. Miller WR, Rollnick S. Entrevista motivacional: preparando as pessoas para a mudança de comportamentos adictivos. Porto Alegre: Artmed; 2001.

21. Dalmolin BM, Lopes SMB, Vasconcellos MPC. A construção metodológica do campo: etnografia, criatividade e sensibilidade na investigação. Saude soc. 2002; 11(2):19-34.

22. Velho G. Observando o familiar. In: Nunes EO, organizador. A aventura sociológica. Rio de Janeiro: Zahar Editores; 1978.

Artigo apresentado em 05/03/2012

Aprovado em 02/05/2012

Versão final apresentada em 25/05/2012 